\title{
A CRIAÇÃO DO GRUPO ESCOLAR SILVEIRA BRUM E AS RELAÇÕES ENTRE MATTRÍCULA, FREQUÊNCIA E FLUXO DE PROMOÇÃO NO ENSINO PRIMÁRIO DO EDUCANDÁRIO (1912-1930)
}

\author{
Talitha Estevam Moreira Cabral ${ }^{1}$ \\ Denilson Santos de Azevedo ${ }^{2}$ \\ Joana D'arc Germano Hollerbach ${ }^{3}$ \\ Wagner Luiz Tavares Gomides ${ }^{4}$ \\ Universidade Federal de Viçosa - UFV
}

\section{RESUMO}

Este trabalho tem por objetivo apresentar alguns dos resultados obtidos através de um projeto de pesquisa realizado na Universidade Federal de Viçosa (UFV), a respeito da criação e primeiros anos de funcionamento do primeiro Grupo Escolar público fundado no município de Muriaé/MG. A investigação aqui problematizada, especificamente, aborda questões relativas à criação do educandário, dando ênfase às questões referentes à matrícula, frequência e fluxo de promoção no ensino primário dessa instituição, em suas duas primeiras décadas de funcionamento. O recorte temporal se justifica em virtude da data de fundação desse estabelecimento de ensino (1912) e o fim da Primeira República no Brasil (1930). Para a consecução da investigação, foram realizadas buscas no Arquivo Público Mineiro (APM) e no acervo existente na atual Escola Estadual Doutor Silveira Brum. Através das pesquisas documentais realizadas foi possível localizar fontes primárias como as Atas de Instalação e Exames, os Termos de Assentamento e Posse, de Visitas Oficiais e Particulares, requerimentos, nomeações, decretos, ofícios e relatórios enviados à Secretaria do Interior do Estado de Minas Gerais no período.

Palavras-chave: História da Educação; Grupo Escolar; Fluxo Escolar.

\section{CREATION GROUP SILVEIRA BRUM AND SCHOOL RELATIONS BETWEEN REGISTRATION, AND FLOW RATE IN PROMOTION OF PRIMARY SCHOOL} (1912-1930)

\begin{abstract}
This paper aims to present some of the results obtained through a research project conducted at Universidade Federal de Viçosa (UFV), about the creation and first years of operation of the first public school group founded in the city of Muriae / MG. The problematized investigation here specifically addresses issues concerning the creation of breed, emphasizing the issues related to enrollment, attendance and promotion flow in primary education from this institution, in its first two decades of operation. The time frame is justified by the date of the founding of this school (1912) and end of the First Republic in Brazil (1930). To achieve the research were conducted search the Arquivo Público Mineiro (APM) and the existing acquis in the current Escola Estadual Doutor Silveira Brum. Through desk research it was possible to locate sources Acts as the primary setup and Examinations, the Terms of Settlement and Possession of Visits Official and Private, requests, nominations, decrees, letters and reports sent Secretary of the Interior of the State of Minas Gerais in the period.

Keywords: History of Education, School Group, School Flow.
\end{abstract}




\section{I- Introdução}

O presente trabalho tem a intenção de apresentar alguns dos resultados alcançados por meio da investigação ${ }^{5}$ realizada a respeito do processo de criação e da cultura escolar instituída nos primeiros anos de funcionamento do Grupo Escolar Silveira Brum (GESB), criado pelo decreto 3.305, de 5 de setembro de 1911 no município de Muriaé/MG e instalado em 7 de agosto de 1912.

A escolha do objeto de pesquisa se justifica, inicialmente, pela inexistência, até a presente data, de estudos científicos a respeito do educandário e da cultura escolar desenvolvida após a sua fundação. Aliado a este fator, a proximidade do centenário do Grupo enfatizou a importância de se estudar a primeira instituição de educação pública seriada no município. A periodização delimitada na pesquisa refere-se ao ano de instalação do GESB (1912) e se desdobra até o ano de 1930, que marca o fim do período da Primeira República no Brasil.

Para o estudo da formação do primeiro grupo escolar desta cidade, realizou-se um levantamento bibliográfico sobre as práticas educativas e a cultura escolar predominante nos grupos escolares criados no Brasil. Buscou-se estudar, ainda, esse movimento no estado de Minas Gerais, bem como as razões que possibilitaram consolidar esse tipo de estabelecimento de ensino em algumas das cidades mineiras, no período da Primeira República (1889-1930).

Ao mesmo tempo, foi feita uma análise das fontes, datadas entre 1912 e 1930, encontradas no Arquivo Público Mineiro, no acervo existente na atual Escola Estadual Doutor Silveira Brum e no Arquivo Público da cidade.

A análise das fontes primárias localizadas, como por exemplo, os livros, artigos, dissertações e teses acerca da escolarização no Brasil e em Minas Gerais durante a Primeira República, aliado à documentação do Grupo, localizada nos arquivos pesquisados, contribuiu para identificar inicialmente algumas características da criação, organização e funcionamento da Escola, observando as transições e inovações vivenciadas pelo ensino primário no Brasil, em Minas Gerais e em recorte mais específico, na cidade de Muriaé.

Através das pesquisas documentais realizadas foi possível localizar fontes primárias como as Atas de Instalação e Exames, os Termos de Assentamento e Posse, de Visitas Oficiais e Particulares, requerimentos, nomeações, decretos, ofícios e relatórios enviados à Secretaria do Interior do Estado de Minas Gerais no período estudado.

Na consulta desses acervos, verificou-se - na maioria dos casos - que não há uma preocupação com a conservação e manutenção documental, ou simplesmente o prédio não apresenta boas condições para o armazenamento, nem organização adequada das fontes, o que dificulta o acesso às mesmas por se encontrarem fragmentadas, em mau estado de conservação ou abandonadas em locais impróprios para o funcionamento de um arquivo. Isso dificulta o trabalho do pesquisador, visto que, conforme relata Bernardes e Delatorre

as falhas nos sistemas de controle da produção e tramitação dos documentos, a acumulação desordenada e a falta de normas e procedimentos arquivísticos comprometem a qualidade das atividades rotineiras, uma vez que dificulta o acesso à informação (BERNARDES e DELATORRE, 2008, p. 7). 
Desse modo, o acesso às fontes documentais criou dificuldades para a consecução dessa pesquisa, em função de lacunas que não possibilitaram uma apreensão mais acurada das informações relacionadas ao objeto de estudo. Não obstante, mesmo com as dificuldades na apreensão dos documentos para a realização da pesquisa, a análise dos materiais elencados possibilitou realizar uma caracterização da escolarização no município, e se a mesma se configurou em consonância com o ensino ministrado no estado de Minas Gerais e no Brasil nesse período.

Baseados nessa documentação, e na análise das informações expostas nas fontes localizadas, foi possível perceber o número considerável de restrições no fluxo de promoção no ensino primário. Sendo assim, este trabalho problematiza as possíveis causas que geraram e mantiveram esse quadro acentuado durante os primeiros anos de funcionamento do GESB.

A priori, iremos contextualizar brevemente a criação dos grupos escolares no Brasil e em Minas Gerais, para posteriormente problematizar a história do primeiro Grupo Escolar da cidade de Muriaé, apresentando aspectos considerados relevantes na história educacional desse estabelecimento de ensino, dando ênfase no que tange aos dados relativos ao fluxo de frequência e promoção no ensino.

\section{II- A criação dos grupos escolares no Brasil, em Minas Gerais, e os antecedentes de sua instalação em Muriaé.}

Muito já foi escrito sobre a formação dos Grupos Escolares no Brasil. Dentre os estudos que realizamos identificamos que a organização do ensino primário brasileiro durante o período imperial (1822-1889) se fez por meio das escolas isoladas. Nesse modelo educacional, o trabalho era de responsabilidade de um único professor da comunidade, que se tornava o dono de sua cadeira ${ }^{6}$. As classes eram heterogêneas e funcionavam de maneira precária, em locais improvisados, comumente na própria residência dos docentes, sem oferecer as mínimas condições de higiene.

Também se depreende que, simultaneamente a essa organização escolar, no referido período, a escolarização doméstica ${ }^{7}$ também foi utilizada. Segundo Guedes Pinto e Fontana (2004), as aulas aconteciam em ambientes cedidos e preparados pelos responsáveis. O pagamento do professor era de responsabilidade do contratante individual ou de um grupo de contratantes.

No final do século XIX e início do século XX, um novo modelo de escola passou a vigorar no Brasil. A partir de 1889, com a instalação da república, o modelo educacional que vigorava até aquele momento, baseado no preceito das escolas domésticas, passa a ser visto como ultrapassado e incapaz de atender aos ideais propagados pelos defensores do novo regime, como democracia, ordem, progresso e amor à pátria.

Os republicanos pretendiam, a partir desse momento, disseminar seus valores, preparando a criança para viver em uma sociedade capitalista. Para atender aos intuitos propostos pelo novo modelo educacional, ocorre um movimento de renovação da escola primária por meio do surgimento dos Grupos Escolares. Essa transformação teve um profundo significado social, político e cultural visto que não representava apenas a "democratização" do acesso à leitura e à escrita, mas a implantação de uma instituição educativa responsável em difundir novos valores, hábitos e deveres.

Esse movimento de renovação da escola primária representou a implantação de uma instituição educativa comprometida com os ideais da república e com as perspectivas de modernização da sociedade brasileira. Nesse sentido, Faria Filho e Vago (2000, p. 37) apontam que 
a mais importante reforma até então realizada na educação primária pública mineira destinada às camadas mais pobres da população, mostra que a mudança de lugar, físico e simbólico - "dos pardieiros aos palácios" -, permitiu a constituição de uma nova cultura escolar em Minas, possibilitando, com isso, uma discussão específica sobre o conhecimento escolarizado e a representação da escola como instituição de fundamental importância para o progresso [...] em face do processo de complexificação social em andamento. O cenário tornou-se propício para afirmação e legitimação de uma pedagogia moderna e científica (FARIA FILHO E VAGO, 2000, p. 37).

Segundo Müller (2000), nesse contexto, destaca-se a figura do professor primário, que precisou ser moldado a fim de desempenhar as novas funções que lhes foram designadas, tais como manter a ordem e a disciplina dos alunos, fiscalizá-los na hora do recreio, executar o programa prescrito, zelar pelo material escolar, entre outras. Desse modo, os professores sofreram intensas modificações em sua maneira de trabalhar. Como forma de contribuir para o bom funcionamento das aulas nas novas escolas que se formavam, as legislações do ensino se preocuparam em regulamentar e fiscalizar o trabalho docente.

Mediante essas inovações, a organização da escola primária na forma de Grupo Escolar levou a uma divisão sistemática do ensino, formando classes com alunos de mesmo nível de aprendizagem. A nova metodologia adotada para esse modelo educacional foi denominada como método intuitivo, o qual implicava na adoção de um projeto concreto, racional e ativo que ia se institucionalizando e sendo construído, ainda que em ritmo diferenciado, nos vários estados brasileiros. Segundo Bencostta (2005) coube ao então Distrito Federal e ao Estado de São Paulo o pioneirismo da implantação dos Grupos Escolares.

Em Minas Gerais, a definição desse modelo educacional como espaço ideal para efetivar o ensino primário ocorreu através da Lei $\mathrm{n}^{\circ}$ 439, de 28 de setembro de 1906, editada no governo de João Pinheiro. No entanto, mesmo implantada, esta lei não garantiu que os grupos escolares se instalassem de maneira uniforme nos municípios mineiros. Segundo Pereira (2004), após a instituição da Reforma foi fundado o primeiro grupo escolar de Minas Gerais, na capital Belo Horizonte, que entrou em funcionamento no dia 05 de fevereiro de 1907. Em seguida foi inaugurado o segundo na cidade de Juiz de Fora e o terceiro em Lavras. Depois deles, esse novo modelo de escola foi se difundindo por todo o Estado, em tempos diferentes.

A criação dos grupos escolares mineiros dependia, quase sempre, de relações políticas existentes entre o poder municipal e o Estado. Assim sendo, na cidade de Muriaé, pode-se atribuir a criação do Grupo Escolar, em 1912, à influência política de Antônio da Silveira Brum, que governou esse município de 1905 a $1920^{8}$.

Em sua obra "O que ficou dos 178 anos da historiografia Muriaeense", Maria Auxiliadora Faria (1995) atribui a este político a maioria das benfeitorias realizadas na cidade durante sua gestão como chefe do executivo. Dentre essas melhorias na cidade, Silveira Brum investiu na criação do primeiro Grupo Escolar público do município.

Todavia, antes de tratar dessa fundação, é importante apontar algumas características da cidade e do ensino até então vigente. Na época estudada, esse município, localizado na Zona da Mata mineira, era grande produtor de café. Os coronéis eram não só a elite econômica como também representavam o poder político da região, com forte influência em Minas Gerais e no país. Esses proprietários das grandes fazendas produtoras 
de café cuidavam de educar seus filhos por meio dos professores particulares, que se limitavam à alfabetização das crianças.

Muriaé manteve essa prática de ensino até o início do século $\mathrm{XX}$, quando foram abertas casas de ensino de nível primário e propedêutico para ambos os sexos, o que representou, tentativas e experiências escolares que pudessem atender o maior número de alunos possível.

Apesar dos colégios particulares fundados na cidade, nem todas as crianças tinham acesso à instrução. Sob a justificativa de atender à população pobre muriaeense, é que a administração de Silveira Brum pretendeu dotar a cidade de escolas públicas gratuitas. No entanto, durante a pesquisa, foi possível perceber que esse novo modelo educacional permaneceu inacessível à população carente de recursos financeiros da cidade. Para que se entenda melhor como se davam os processos educacionais no Grupo, nos dispusemos a analisar o histórico de sua criação e o cotidiano escolar nos primeiros anos de funcionamento.

Criado pelo decreto 3.305, de 5 de setembro de 1911, o GESB foi inaugurado em 07 de agosto de 1912 sob a direção do professor José Gonçalves Couto, que depois de nomeado por ato do Sr. Governador do Estado, Júlio Bueno Brandão, em 12 de janeiro de 1912, permaneceu no cargo até 13 de abril de 1936, quando se aposentou.

O corpo de profissionais compunha-se, inicialmente, de oito professores da cidade, muitos lecionando gratuitamente. No primeiro relatório de Gonçalves Couto enviado à Secretaria do Interior percebe-se que era:

[...] de 8 o número de cadeiras existentes neste Grupo, regidos pelos seguintes professores: d. Maria Brandão Lobato, 4 amno mixto; d. Julieta Oliveira de Macedo, $3^{\circ}$ amno mixto; d. Amélia Lopes, 2 amno feminino, d. Estephania Maria do Patrocínio, $2^{\circ}$ amno masculino; d. Maria Amélia de Figueiredo, $1^{\circ}$ amno feminino; d. Amélia Soares Figueirero, $1^{\circ}$ amno mixto; Sr. Henrique Silva, $1^{\circ}$ amno masculino, $1^{\text {a }}$ classe; Lívio de Castro Carneiro, $1^{\mathrm{o}}$ amno masculino, $2^{\mathrm{a}}$ classe. (RELATÓRIO DO MOVIMENTO ESCOLAR, 1913, s/p)

A partir da leitura das informações pesquisadas, podemos notar o rigor incorporado nas práticas implantadas no Grupo. Além disso, nos documentos, há uma exaltação dos ideais de "Ordem e Progresso" trazidos pela República, que são identificados em diversos momentos no GESB. Nos relatórios anuais localizados podemos perceber que as comemorações da Independência do Brasil e da Proclamação da República sempre eram muito festejadas.

Outro documento que indica a disseminação dos ideais republicanos é um relatório de visita de particulares, em que um dos visitantes escreve:

Depois de percorrermos todos os salões de estudo, onde apreciei graciosos e complicados trabalhos manuaes, e outras cousas, soou, eloquentemente, a sineta que nos annunciava o recreio infantil. Instantes depois passava, em formatura elegante, a alegre criançada. A nota destaque do momento foi a continência á bandeira nacional. $\mathrm{O}$ que mais me admirou foi o respeito com que [...] saudaram o auriverde pendão. [...] todos os apparelhos exigidos pela pedagogia hodierna alli se encontram, no mais perfeito estado de asseio e conservação, prestando os seus relevantes serviços á causa da vida pratica [...] a mnemotechnia é observada com todo o rigor [...] (RELATÓRIO DE VISITA DE PARTICULARES, 1913, s/p). 
Nesta citação percebemos além da prática nacionalista realizada pelos alunos no GESB, a presença de instrumentos metodológicos para o exercício de uma pedagogia que aproveita o instinto e a tendência natural da criança, dando significado prático à aprendizagem.

Para ratificar o procedimento metodológico utilizado no Grupo, localizamos outro relatório de visita de particulares, datado de 28 de dezembro de 1912, que identifica a utilização da lição de coisas proposta pelo método intuitivo neste estabelecimento de ensino. Uma equipe de visitantes escreve em relatório explicando porque o educandário se configurava como um exemplo de modelo escolar:

É que nelle se conjugam e admiravelmente se casam os melhores mhetodos pedagógicos com a mais séria disciplina e ordem. As licções ministram-se por processos brandos e altamente profícuos fiados na intuição e analyse dos factos múltiplos que constituem a essência da escola moderna. A noção das coisas caminha da mais simples para a mais complexa, ensinando a mente infantil para dellas se apreender suavemente para a vida independente e autônoma do individuo na sociedade [...] nunca imaginamos que em quatro escassos mezes de aulas tanto se conseguisse de resultados esplendidos nesta casa [...] (RELATÓRIO DE VISITA DE PARTICULARES, 1912, s/p)

Desse modo, baseado no método intuitivo de ensino, as disciplinas trabalhadas seguiam uma normatização do Regulamento Geral da Instrução e, para finalizar o período letivo, os alunos compareciam aos exames finais, sendo julgados por seus conhecimentos e aprovados ou retidos por meio de atividades escritas e orais. Aos aprovados expedia-se diploma de aprovação em exame final, conforme podemos perceber na imagem abaixo:

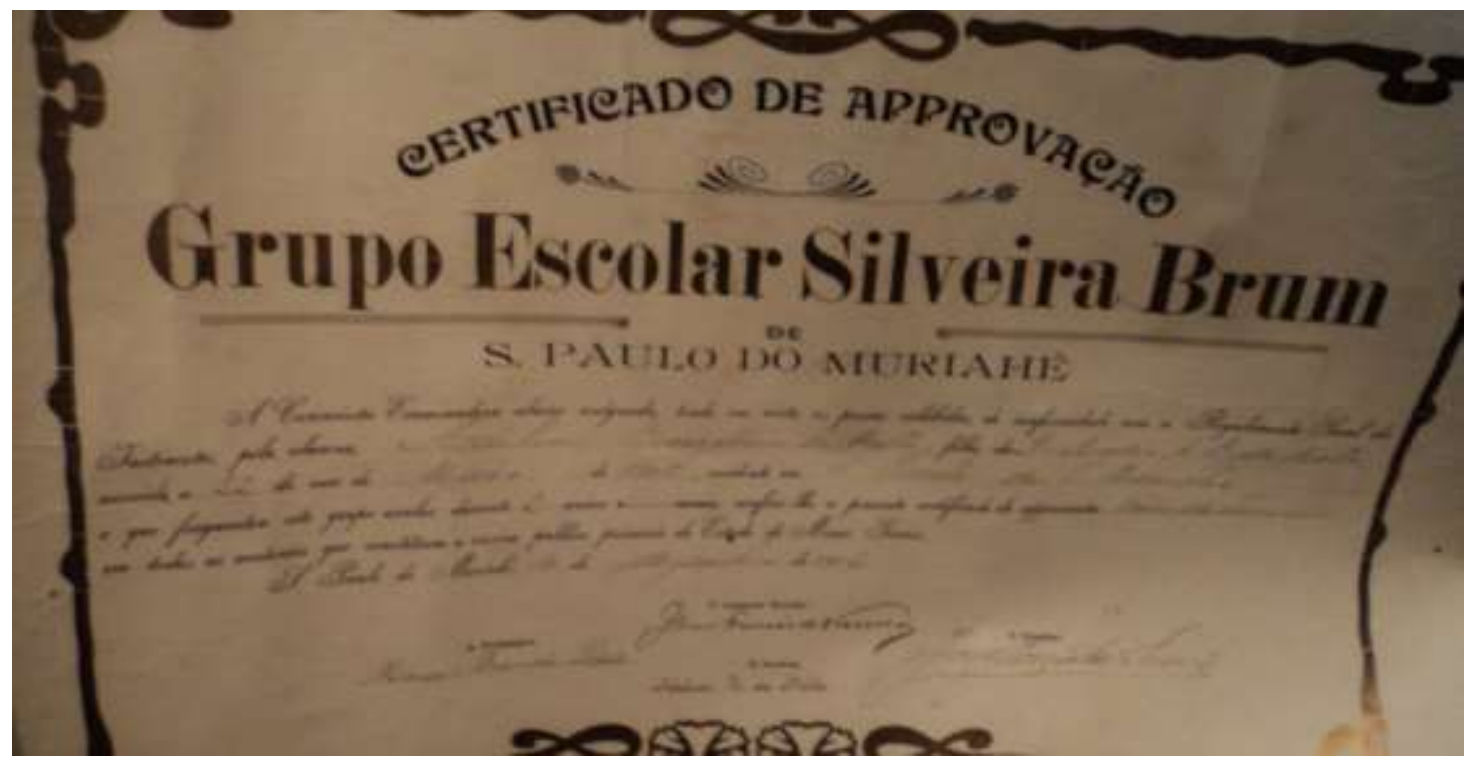

Fonte: Acervo da Escola Estadual Doutor Silveira Brum.

Legenda: "A comissão examinadora abaixo assignada, tendo em vista as provas exibidas, de conformidade com o Regulamento Geral da Instrucção, pelo alumno , filho de , nascido a _ do mês de de $\_$, residente em $\_$e que fresente certificado de approvação confere-lhe o presente certificado de approvação
público primário do estado de Minas Geraes. S. Paulo do Muriahé Assinaturas: A professora; $\mathrm{O}$ inspetor escolar; O director; $\mathrm{O}$ alumno. 
Esse certificado, e as demais informações pesquisadas nos acervos contribuem para a identificação das práticas pedagógicas no GESB, em que podemos perceber a intensa preocupação do diretor em averiguar a competência dos professores no exercício da profissão docente.

Essa situação pode ser comprovada com a leitura dos relatórios enviados à Secretaria do Interior, em que, quase sempre, o diretor Gonçalves Couto fazia menção aos professores do Grupo. Em 1914, especificou o comportamento de cada um, referindo-se à ordem, obediência e trabalhos realizados. No relatório do GESB de 1915, o diretor pontua o trabalho de cada professor, chamando a atenção na maioria das vezes. Os únicos elogios destinados aos docentes foram feitos a duas professoras, quando disse que "em suas classes há sempre muito boa ordem e irreprehensivel disciplina" (s/p). Sobre os demais, o diretor critica negativamente e faz objeções para mudança de postura em sala de aula.

Além do rigor disciplinar exercido com os professores, outro aspecto relevante que nos chamou a atenção ao estudar os documentos encontrados foi a relação estabelecida pelo diretor Gonçalves Couto com os pais dos alunos, no sentido de informá-los a respeito das penalidades e da imposição da disciplina aos discentes.

No controle das atividades realizadas no educandário, além do diretor, surge a figura do inspetor escolar, também responsável em gestar o funcionamento das práticas pedagógicas que vinham sendo implementadas no Grupo. A ele cabia dirigir a parte técnica do ensino e no exercício de sua autoridade, fiscalizar o Grupo por intermédio dos seus auxiliares.

No Grupo Escolar Silveira Brum, constantes visitas de oficiais e particulares delineavam os trabalhos realizados. Os relatórios dessas inspeções eram quase sempre elogiando o bom desempenho da instituição. É importante salientar que as impressões relatadas nos cadernos de visitas localizados sempre se preocupavam em apresentar a organização, a ordem e disciplina dos alunos, conforme percebe-se na passagem presente no relatório de visita de inspetores:

\footnotetext{
Comparecendo a este Grupo, de $1^{\mathrm{o}}$ a 9 do corrente, em serviço de inspeção, verifiquei além da boa ordem, excellente disciplina, irreprehensivel asseio e rigorosa limpeza, a louvável dedicação do corpo docente a este exemplar instituto de ensino, confiado á competente direcçao do professor José Gonçalves Couto, incançavel no exacto cumprimento de suas attribuições. S. Paulo do Muriahé, 9 de abril de 1913. Inspetor de Ensino da $11^{a}$ região, Joao Ferreira. (RELATÓRIO DO INSPETOR DE ENSINO, 1913, s/p)
}

Ao analisar os relatórios de visitas, podemos perceber que as inspeções deram grande ênfase aos aspectos curriculares, às orientações pedagógicas, didáticas e de ensino, além de preconizar o momento correto de avaliação. Tais narrativas acabam apontando certas características da escola e possíveis pontos para correção de rumos, pois diante dos apontamentos deixados nesses relatórios, o diretor buscava analisar e adequar sua forma de gestar as atividades desenvolvidas no Grupo.

Após a apresentação de informações sobre o cotidiano escolar do GESB, bem como a respeito dos sujeitos envolvidos no processo educativo e das relações tecidas entre os mesmos em seu interior, apresentaremos considerações referentes à matrícula, a frequência escolar e aos demais aspectos alusivos ao fluxo de promoção nesse educandário, nos anos de 1912 a 1930.

III- Matrícula, frequência e fluxo de promoção no ensino primário do GESB. 
Após discutir o processo de criação dos grupos escolares no Brasil, em Minas Gerais e no município muriaeense no início do século XX, pretendemos analisar dois aspectos relevantes que fizeram parte da história do GESB: a obstrução no fluxo de promoção e a diferença entre as informações obtidas, sobretudo, a respeito da matrícula e frequência dos alunos.

Em visita ao arquivo Público Mineiro e ao acervo da atual Escola Estadual Doutor Silveira Brum, encontramos em ofícios e relatórios enviados à Secretaria do Interior, evidências que demonstraram que a matrícula no educandário era realizada em consonância com as exigências presentes no Regulamento da Instrução, sendo feitas durante o mês de Janeiro, com exceção do primeiro ano de funcionamento do Grupo, no qual as matrículas foram realizadas no período de 18 de julho a 7 de agosto:

Organizado o Grupo, foi por V. Excelência, em offício de 13 de julho de 1912 numero 181, autorizado a, pelo praso máximo de vinte dias abrir neste estabelecimento de ensino a matrícula: "[...] Mandei imprimir boletim que [...] foram espalhados pela cidade, avisando aos interessados que se, achava aberta a matricula no Grupo. De 18 de julho a 7 de agosto matricularam-se 568 alumnos, sendo 320 meninos e 248 meninas [...] é de 8 o número de cadeiras existentes neste Grupo (RELATÓRIO DO MOVIMENTO ESCOLAR, 1913, s/p).

Em 1914, José Gonçalves Couto se organizou para que a matrícula ocorresse da maneira mais eficiente possível, segundo consta em seu relatório:

De acordo com o Regulamento, fiz no dia 7 de janeiro espalhar boletins pela cidade avisando que se achava neste grupo de 12 as 4 da tarde dos dias uteis aberta a matrícula. Dividi a cidade em 9 secções, encarregando cada professor da matrícula numa destas secções. A medida tomada foi excelente: de 7 a 31 de janeiro matricularam-se 663 alumnos, 340 masculino e 323 feminino (RELATÓRIO DO MOVIMENTO ESCOLAR, 1914, s/p).

Dessa maneira, entendemos que a divulgação realizada a respeito do GESB estava alcançando seu objetivo inicial de levar instrução ao maior número de crianças possível, isso se verifica ao analisar as matrículas iniciais no educandário.

Nos materiais pesquisados referentes ao período abarcado neste trabalho, encontramos os dados relativos à matrícula inicial dos anos de 1912 a 1925, com lacunas nos anos de 1913, 1916, 1917, 1922 e 1923, conforme apresenta o gráfico abaixo:

\section{Matrículas no Grupo Escolar Silveira Brum}

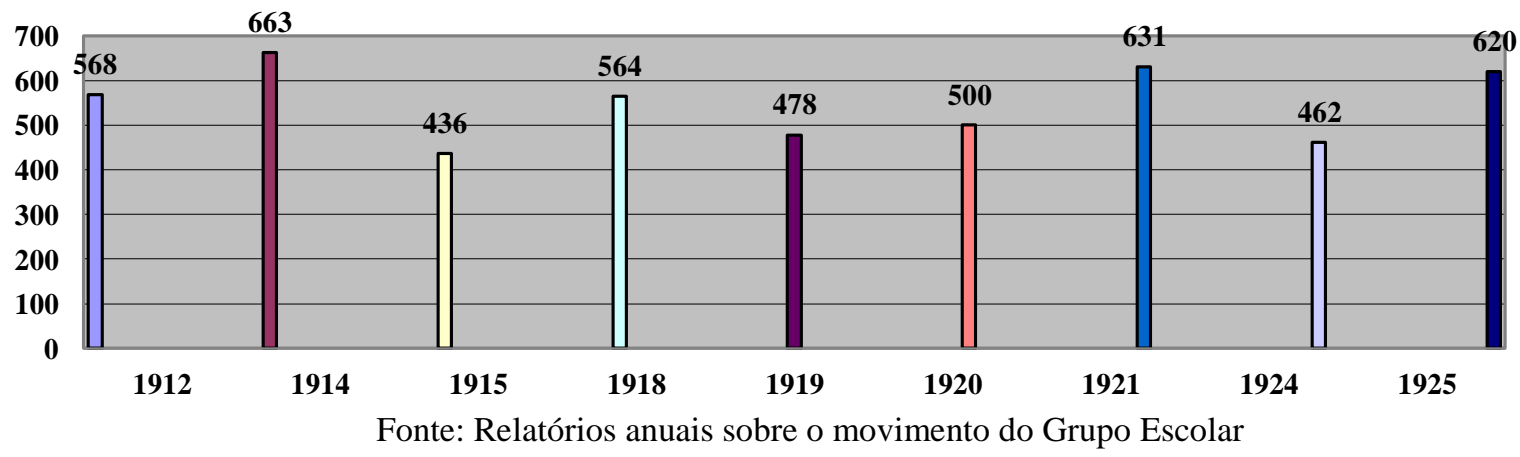

Revista HISTEDBR On-line, Campinas, $n^{\circ}$ 52, p. 138-154, set2013-ISSN: 1676-2584 145 
Analisando as informações supracitadas percebemos que o ano com maior número de matrícula inicial foi 1914, isso se deve provavelmente à novidade representada pelo Grupo após seus dois primeiros anos de funcionamento.

Podemos também observar que há uma regularidade de oscilação do número de matriculados. No entanto, pode se dizer que estes valores eram relativamente elevados, o que possivelmente tenha motivado a divisão em dois turnos no educandário. É importante ressaltar que, com as análises realizadas foi possível perceber ainda, que a relação entre meninos e meninas matriculados no Grupo Escolar Silveira Brum demonstra um equilíbrio entre esses números em ambos os sexos. Na maioria dos casos notificados, estes dados são praticamente os mesmos, variando um pouco para mais ou para menos.

No primeiro ano de funcionamento, de 18 de julho a 7 de agosto de 1912 matricularam-se 568 alunos, sendo 320 meninos e 248 meninas. Em 1914, de 7 a 31 de janeiro matricularam-se 663 alumnos, 340 do sexo masculino e 323 feminino. Já no ano de 1918 matricularam-se neste Grupo 564 alunos, sendo 306 do sexo masculino e 258 do sexo feminino. Ainda na segunda década de funcionamento do GESB, no ano de 1925, essa proximidade do número de meninos e meninas matriculados permaneceu, foram matriculados 620 estudantes, dos quais 328 eram do sexo masculino e 292 eram do sexo feminino. Todavia, percebe-se que apesar da pequena diferença, em todos estes anos a maioria de matriculados foi do sexo masculino. Na divisão das salas, encontram-se relatos de separação entre os sexos, mas também nota-se que existiam as salas mistas.

Persistindo na análise do gráfico percebe-se que o ano de 1921 recebeu o segundo maior número de matrículas, seguido do ano de 1925 , ano com o $3^{\circ}$ maior contingente de alunos matriculados. Isso pode ser um demonstrativo da credibilidade associada ao Grupo na sua segunda década de funcionamento.

Mediante as informações anteriores podemos perceber que o fluxo de alunos no Grupo era suficientemente intenso, o que resultou, conforme citado anteriormente, na divisão dos turnos no colégio. Isso pode ser verificado nos documentos emitidos, na maioria das vezes, pelo diretor, ao notificar o elevado número de matriculados neste estabelecimento. Não obstante, com base em alguns dados colhidos nos materiais pesquisados, percebemos que há um paradoxo entre o número de alunos matriculados e número de frequentes, o que nos levou a realizar uma análise mais detalhada a respeito dessa situação.

Nos documentos analisados, encontramos a relação matrícula versus frequência relativa aos anos de 1912, 1914, 1918 e 1925 e percebemos que o contingente de alunos que se matriculava no Grupo em todos esses anos era mais elevado do que o número de crianças que permaneciam no mesmo no decorrer do ano. No gráfico abaixo, é possível fazer uma análise comparativa entre esses dados:

Relação Matrícula X Frequência no GESB:

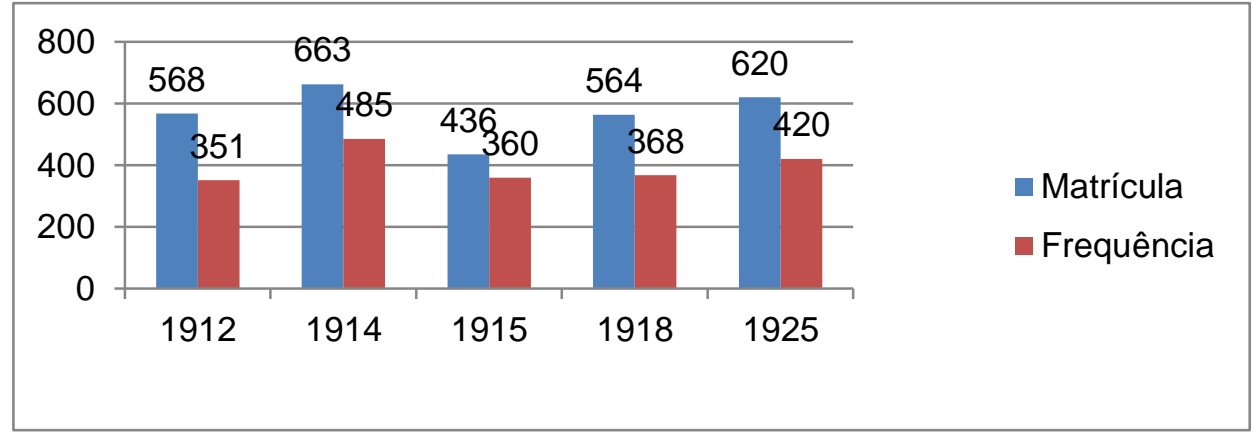

Fonte: Relatórios anuais sobre o movimento do Grupo Escolar 
Se analisarmos o gráfico, podemos perceber que em todos os anos retratados, a frequência foi inferior à matrícula. O ano de 1912 é o que houve o maior contraste, com 351 frequentes dos 568 matriculados, ou seja, aproximadamente $61 \%$ dos alunos apresentaram presença contínua no Grupo.

Nos anos seguintes, esse desnível também se mostrou evidente: em 1914 foram 663 matriculados contra apenas 485 assíduos. O ano de 1915 foi o que essa relação mais se aproximou, tendo como frequência cerca de $82 \%$ dos alunos. Já em 1918, o desnível volta a se manifestar, com apenas 368 alunos frequentes dos 564 registrados no início do ano, o que permaneceu no ano de 1925, com 620 inscritos versus 420 assíduos, o que representa uma margem de $67 \%$.

Esses dados contraditórios nos levaram a investigar se não havia, no estado de Minas Gerais, políticas que garantissem a permanência dos alunos nas salas de aula. Nas pesquisas realizadas, foi possível constatar que a legislação de ensino do Estado, destaque para a lei $\mathrm{n}^{\circ} 800$, de 27 de setembro de 1920, definia a obrigatoriedade do ensino para as crianças de 07 a 14 anos, tornando a frequência indispensável, não podendo o aluno ter mais de três faltas mensais, exceto em caso de moléstia.

Todavia, não era essa a realidade no Grupo Escolar Silveira Brum, em que muitas crianças eram matriculadas no início do ano letivo, mas não acompanhavam assiduamente as aulas durante o mesmo, devido a várias causas. Diante deste quadro, decidimos investigar quais os principais motivos para essa disparidade entre matrícula e frequência.

Uma das possíveis justificativas a serem destacadas é o fato de muitos pais precisarem dos filhos para ajudar no sustento da família, desse modo, as crianças carentes financeiramente tendiam a abandonar a vida escolar, mesmo tentando conciliar trabalho e estudo. Outro fator relevante é que muitos pais ou responsáveis matriculavam as crianças no Grupo apenas para cumprimento da Lei, e não se importavam nem fiscalizavam a assiduidade dos filhos nas escolas.

Supõe-se, ainda, que mesmo com a centralidade do prédio do Grupo, as crianças de bairros afastados do centro ou da Zona Rural encontravam dificuldades de se locomover até a escola. Por isso, outro possível empecilho para a permanência dos alunos no Grupo se devia ao fato dos pais resistirem em mandar seus filhos para a escola, pois insistiam em ministrar a educação dos filhos em casa ou em escolas particulares próximas a suas residências.

Outra suposição, diz respeito à dificuldade das crianças em acompanhar o novo modelo pedagógico proposto pelos republicanos, com a criação dos Grupos Escolares. A nova metodologia de ensino, baseada principalmente na Lição das Coisas, poderia afastar as crianças das salas de aula, pois elas tinham medo de não conseguirem se adaptar ao método e aos conteúdos.

Entendidas as possíveis causas para o desnível entre matriculados e frequentes no GESB, retornamos aos dados obtidos através das fontes consultadas. Desse modo, persistindo na análise da documentação encontrada, principalmente as Atas de Promoção, outra situação que nos chamou a atenção faz referência à obstrução do fluxo escolar. Ao final do ano letivo, após a realização das avaliações mensais, o diretor escrevia, em relatório, o número de alunos promovidos de uma série a outra no ensino.

Para aprovação, o aluno deveria ter média de aproveitamento, procedimento acima de cinco e frequência mínima às aulas, podendo se ausentar dos trabalhos escolares três vezes ao mês. Os nomes dos aprovados eram lavrados nos "Termos de Promoção", que eram escritos por classe, constando data, nome de cada professor e a série lecionada, seguida do nome dos alunos promovidos e não promovidos. Tal ata se encerrava com um 
resumo numérico das promoções e a qualificação da aprovação dos alunos (com distinção, plenamente ou simplesmente).

A leitura das "Atas de Promoção" encontradas sobre o GESB nos mostra que os exames neste educandário ocorriam quase sempre no mês de novembro ou dezembro. A forma pela qual eram realizadas essas avaliações não está explícita em tais documentos, todavia percebe-se que há uma preocupação em classificar e ordenar, de acordo com os conceitos, os estudantes da escola.

Ao analisar a relação dos alunos promovidos no ensino, um aspecto relevante diz respeito à obstrução do fluxo escolar, principalmente no $1^{\circ}$ ano primário. Segundo a pesquisa realizada, essa situação já podia ser percebida logo no primeiro ano de funcionamento do GESB.

Os gráficos abaixo apresentam alguns dos dados encontrados a respeito da aprovação em exames dos alunos do referido Grupo:

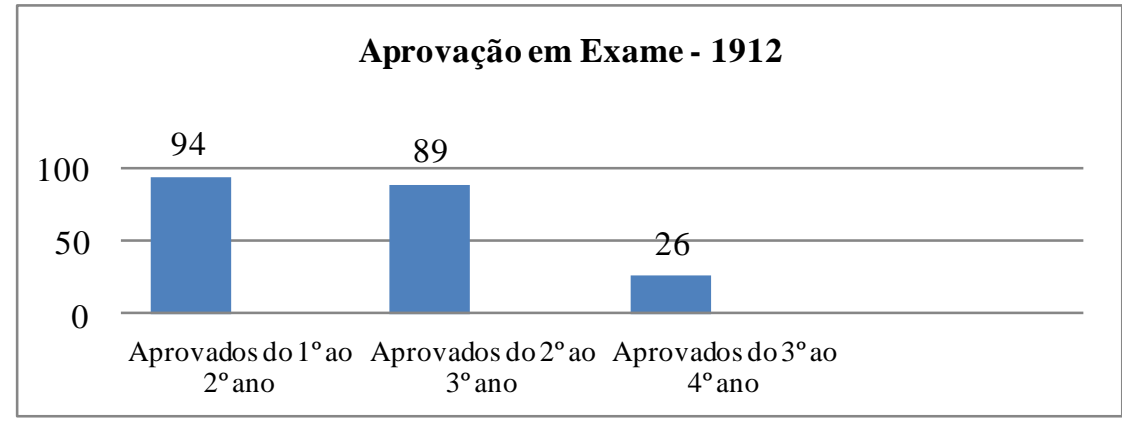

Fonte: Atas de Exame e Relatórios de Promoção.

Se analisarmos o número de matriculados no ano de 1912, surpreende-nos o número de alunos promovidos, principalmente do $1^{\circ}$ ao $2^{\circ}$ ano. Das 363 crianças registradas nessa série de ensino, apenas $25 \%$ foram promovidas ao $2^{\circ}$ ano. A aprovação do $2^{\circ}$ ao $3^{\circ}$ ano se demonstra mais equilibrada, com 89 dos 119 matriculados progredindo de série no ensino. Do $3^{\circ}$ ao $4^{\circ}$ ano, menos da metade dos alunos foram promovidos, apenas 26 dos 65 inscritos. Esses dados nos instigam a entender o porquê de tão baixos níveis de aprovação nos exames, principalmente do $1^{\circ}$ ao $2^{\circ}$ ano. Segundo Azevedo e Carvas (2011, p.10),

os alunos ainda no início da vida escolar enfrentavam muita dificuldade para acompanhar as aulas de maneira satisfatória. O ritmo escolar imposto aos alunos, ainda inexperientes na vida acadêmica, se mostrava um desafio, muitas vezes não superado pelos estudantes, o que acarretava na evasão escolar ou na retenção e não progressão entre as séries.

No ano de 1916, não encontramos dados relativos à promoção em cada série, mas uma análise interessante diz respeito ao número de alunos que concluíram o ensino primário: 


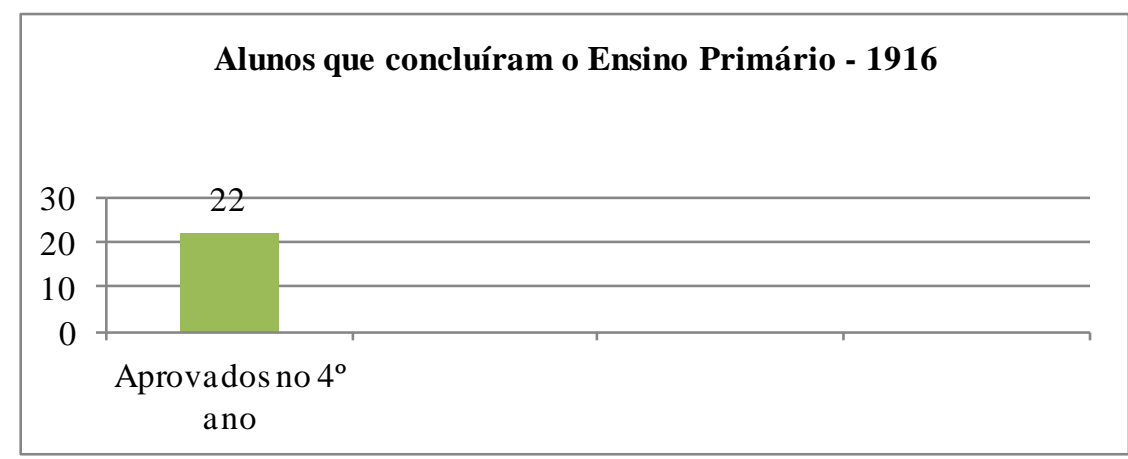

Fonte: Atas de Exame e Relatórios de Promoção.

Se pensarmos que, em 1912, primeiro ano de funcionamento do Grupo, o número de alunos matriculados no $1^{\circ}$ ano foi de 363 , e se nos apoiarmos na ideia de que, para se concluir o ensino primário, se levaria quatro anos, percebemos que a aprovação de 22 crianças no $4^{\circ}$ ano em 1916 comprova que 341 crianças não acompanharam a promoção conforme seria o esperado. Nota-se, então, uma representativa desistência de alunos quando se compara com o número de matriculados no início de 1912. Desse modo, pode-se perceber que "muitos ficaram pelo caminho, talvez pela frágil condição socioeconômica ou pelo próprio código utilizado pela escola na comunicação das suas atividades pedagógicas" (ABREU JUNIOR e GUIMARÃES, 2011, p. 7-8).

Em relatório sobre a promoção dos alunos em 1919, o diretor Gonçalves Couto especifica o número de aprovados por turma, e qual o conceito obtido pelas crianças durante os exames:

Foi o seguinte o resultado dos exames realizados neste grupo nos dias $15,16,17$ e 18 de janeiro deste anno:

$1^{\circ}$ anno

Foram approvados 45 alumnos: 2 com distinção, 37 plenamente e 6 simplesmente. Não preparados -14 .

$2^{\circ}$ anno

Approvados - 31 alumnos: plenamente, 20. Simplesmente, 11. Considerados não preparados, 5 .

$3^{\circ}$ anno

Approvados - 27 alumnos: 2 com distinção; 18 plenamente; 7 simplesmente. Considerados não preparados -6 .

$4^{\circ}$ anno

Approvados - 33 alumnos: com distinção - 12; plenamente, 21. Todos que compareceram, passaram. Aos alumnos que concluíram o curso - 17 meninas e 16 meninos, - foram conferidos os certificados de approvaçao, em sessão solene (RELATÓRIO DE PROMOÇÃO NO ENSINO, 1919, $\mathrm{s} / \mathrm{p})$.

No ano de 1925, não encontramos detalhamento nenhum a respeito das aprovações. Não foi possível localizar dados referentes à matrícula e frequência em cada turma para fins de comparação entre frequentes e promovidos no ensino. Todavia, sabemos que a matrícula inicial total nesse ano foi de 620 alunos e o número total de aprovados foi 336, o que representa $54 \%$ das crianças, pouco mais da metade de matriculados foram promovidos nesse ano, conforme apresenta o gráfico a seguir: 


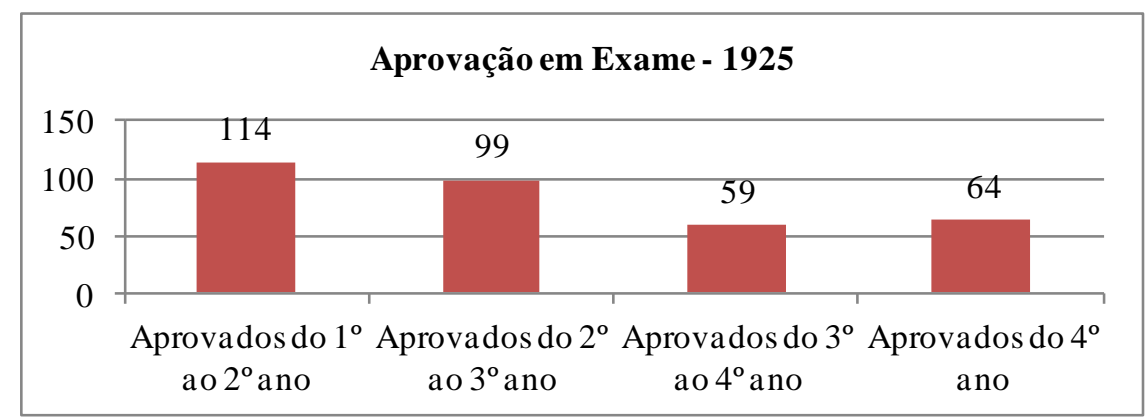

Fonte: Atas de Exame e Relatórios de Promoção.

Já no gráfico abaixo, apresentamos o número de alunos promovidos e não promovidos em 1926:

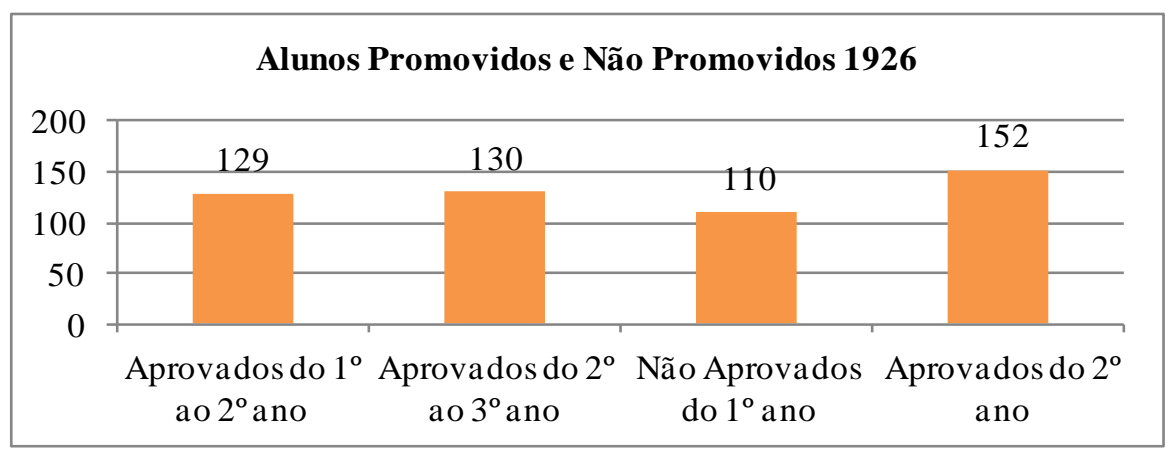

Fonte: Atas de Exame e Relatórios de Promoção.

Percebe-se, através do registro desses dados, que foi representativo o número de reprovações ocorridas no ano de 1926, pois, dos 229 alunos matriculados no $1^{\circ}$ ano, apenas 129 foram promovidos para o $2^{\circ}$ ano, o que representa $56 \%$ das crianças.

Supostamente, esse desnível entre promovidos no ensino representava um problema à gestão pedagógica do Grupo. Em Muriaé, não encontramos evidências que comprovassem os reais motivos para a ausência das crianças na escola e a obstrução no fluxo escolar. Inclusive, este é um ponto que gerou contradições e dúvidas, visto que a discrepância entre esses dados possivelmente era indicativo de falha no processo educativo que contemplava desde a admissão dos alunos até a permanência e promoção dos mesmos no educandário. Diante desde quadro, a preocupação em manter as crianças no GESB deveria ter sido, sobretudo, uma das principais intenções do diretor que pretendia tornar o estabelecimento referência para o Estado.

Apesar das dificuldades em compreender os reais motivos da não-promoção e nãopermanência dos alunos no Grupo de Muriaé no início do século XX, percebe-se que, em outras localidades, o que acontecia era possivelmente a situação retratada anteriormente no texto: o fato das crianças carentes precisarem trabalhar para ajudar seus pais, bem como a dificuldade de aprendizagem e adaptação aos novos conteúdos e métodos difundidos através do novo modelo educacional (FARIA FILHO, 2000).

\section{Considerações finais:}

A construção do trabalho apoiou-se nos estudos dos teóricos da História da Educação Brasileira, particularmente os historiadores da educação mineira, os quais 
subsidiaram a realização da pesquisa. O cotejamento dos dados priorizou o estudo sobre as práticas educativas e a cultura escolar predominante nos grupos escolares criados no Brasil no início do século XX. Verifica-se que até o final do século XIX existiam diferentes formas de se oferecer o ensino em todo o Brasil. Haviam as escolas domésticas através de professores particulares, as escolas particulares e as escolas isoladas, tanto rurais quanto urbanas. Muriaé praticamente não difere desse modelo de escolarização até os anos de 1912, com a instalação do primeiro grupo escolar público do município.

Os resultados obtidos demonstram que a criação do Grupo Escolar Silveira Brum na cidade de Muriaé foi o marco inicial de um modelo de escolarização que surge em todo o país, incluindo o estado de Minas Gerais. Esse estudo tornou possível observar que o educandário criado pretendia atender as exigências da República, com a divisão do trabalho, de modo a controlar os espaços e tempos escolares. A nova metodologia de ensino utilizada contava com a figura do diretor como responsável pela organização do trabalho, com a presença de um professor como regente do ensino elementar a um grupo de alunos divididos por séries no ensino primário. Essas modificações nas práticas escolares contribuíram para concretizar uma aprendizagem progressiva, com a gradativa implantação de um trabalho pedagógico cada vez mais embasado nos princípios republicanos e patrióticos.

Com a análise dos primeiros documentos produzidos a respeito da instalação e do funcionamento do Grupo Escolar Silveira Brum, procuramos descortinar alguns dos aspectos que permearam o cotidiano do Grupo durante o período em foco. Nesse contexto, um aspecto que chamou a atenção está relacionado à discrepância entre o número de matrícula e frequência, e de promovidos no ensino, fato que esteve presente desde a criação do Grupo Escolar, perdurando durante décadas.

É de supor que tal condição representava um problema à gestão pedagógica do GESB, não obstante tais motivos para esse desnível não foram explicitamente identificados. Pode-se inferir, conforme suprarreferenciado, que a pouca importância dada ao ensino primário das crianças; a tentativa de conciliar trabalho e estudo; e ainda, o fato de muitos pais continuarem ministrando a educação dos filhos em escolas particulares ou em casas, possam ter contribuído para essa situação.

Desse modo, o estudo realizado nos leva a crer que os desafios vivenciados nas questões referentes ao acesso e permanência dos alunos nas instituições educativas hoje são resultados de problemas históricos, construídos por uma sociedade desigual. E, nesse sentido, a história da educação auxilia na compreensão de questões atuais, não com o intuito de solucionar os problemas que surgem, mas, com a intenção de lançar luz a aspectos já vivenciados em outros momentos históricos, capazes de orientar possibilidades e caminhos.

Nesse mote, percebemos a questão da matrícula e frequência no início do século $\mathrm{XX}$ como um sinalizador de uma dificuldade que parece permanecer nos dias atuais. Mais de um século se passou, e ao olharmos para trás, percebemos que os nós do tempo persistem. Essa situação complexa aparentemente está imbricada numa série de outros fatores sociais, econômicos e culturais, revelando uma possibilidade de identificar as raízes da desigualdade social como pano de fundo para os desníveis entre matrícula e frequência nas escolas. Trata-se de um problema histórico em que se propaga o direito à instrução a todos, inclusive à classe subalterna, não obstante não se efetivam medidas que assegurem não apenas a chegada ao espaço escolar, mas também sua eficácia e condição de manutenção. O que se vê, de maneira diferenciada nos diversos momentos históricos, são medidas assistencialistas que não resolvem o problema, mas o dissimula. É o caso das Caixas Escolares (início do século XX) e das Bolsas-Auxílio (início do século XXI). 
Outrossim, essa condição nos leva a crer que são necessárias mudanças efetivas em benefício da educação por meio de ações que permeiem questões não somente educacionais, mas político-econômicas e sociais também, permitindo a ascensão social e a equalização das igualdades de oportunidades a todos, a começar pelo acesso de qualidade e com a permanência garantida nos estabelecimentos de ensino.

\section{Referências}

\section{Documentos pesquisados em Arquivos:}

GRUPO ESCOLAR SILVEIRA BRUM. Atas de Instalação, posse, exames, etc. 19121924. (Arquivo Escola Estadual Doutor Silveira Brum).

GRUPO ESCOLAR SILVEIRA BRUM. Ofícios enviados e recebidos da Secretaria de Educação do Estado. 1912 a 1930. (Arquivo Escola Estadual Doutor Silveira Brum).

GRUPO ESCOLAR SILVEIRA BRUM. Termos de Visitas Oficiais; Termos de Visitas Particulares (1912-1927). (Arquivo Público Mineiro e Escola Estadual Doutor Silveira Brum).

GRUPO ESCOLAR SILVEIRA BRUM. Cadernos de avaliação e certificados de aprovação dos alunos. 1913-1916. (Arquivo Escola Estadual Doutor Silveira Brum).

GRUPO ESCOLAR SILVEIRA BRUM. Relatório do Diretor. 1913-1919. (Arquivo Escola Estadual Doutor Silveira Brum).

GRUPO ESCOLAR SILVEIRA BRUM. Atas de Instalação e Exames; Relatórios do diretor; Termos de Assentamento e Posse; Visitas Oficiais e Particulares; diplomas; requerimentos; nomeações; decretos; licenças; procurações; frequência dos professores elou alunos 1912-1930. (Arquivo Público Mineiro).

Revista de Historiografia Muriaeense. Ano II, nº 2 - Muriaé/MG. Maio, 1979.

\section{Livros, artigos e periódicos:}

ABREU JUNIOR, Laerthe de Moraes; GUIMARÃES, Paula Cristina David. A cultura material escolar como fonte de pesquisa das práticas escolares em São João Del-Rei (1930-1945). Revista Educação: Teoria e Prática, 2011.

AZEVEDO, Denilson Santos de; CARVAS, Giovanna Maria Abrantes. GRUPO ESCOLAR ANTÔNIO MARTINS (1930-1945): CONSIDERAÇÕES ACERCA DAS RESTRIÇÕES NO FLUXO DE PROMOÇÃO DO ENSINO PRIMÁRIO. Disponível em: www.sbhe.org.br/novo/congressos/cbhe6/conteudo/file/554.doc. Acesso em 19 de dezembro de 2011.

BENCOSTTA, Marcus Levy Albino. Grupos escolares no Brasil: um novo modelo de escola primária. In: BASTOS, M.H.C. \& STEPHANOU, Maria (Orgs). Histórias e Memórias da Educação no Brasil. Petrópolis: Vozes, 2005, p. 68-76.

BERGER, Miguel André \& ALMEIDA, Anne Emile Souza de. A instrução pública em Sergipe na era da modernidade - analisando a trajetória dos Grupos Escolares. In: Congresso Brasileiro de História da Educação: A Educação Escolar em Perspectivas Históricas, 3, 2004, Paraná. Anais. CD - ROM. 
BERNARDES, Ieda Pimenta; DELATTORE, Hilda.(Coords.). Gestão Documental Aplicada. São Paulo: Arquivo Público do Estado de São Paulo, 2008. 54 p.

CABRAL, T. E. M.; \& AZEVEDO, D. S. (2012). A instalação e constituição do Grupo Escolar nas cidades de Muriaé e Ponte Nova (1907 - 1930): análise de acervo e memórias. Viçosa. Relatório PIBIC/FAPEMIG

CARVALHO, Marta Maria Chagas de. A escola e a República. São Paulo: Brasiliense, 1989.

FARIA FILHO, Luciano Mendes de. Dos Pardieiros aos Palácios - Cultura escolar e urbana em Belo Horizonte na Primeira República. Passo Fundo: UPF, 2000.

FARIA FILHO, Luciano Mendes de; VAGO, Tarcísio Mauro Vago. A Reforma João Pinheiro e a Modernidade Pedagógica. In: FARIA FILHO, Luciano Mendes de, PEIXOTO, Ana Maria Casasanta (Orgs.). Lições de Minas: 70 anos da Secretaria da Educação. Belo Horizonte: Secretaria de Estado da Educação de Minas Gerais, 2000.

FARIA, Maria Auxiliadora de. O que ficou dos 178 anos da história de Muriaé. Muriaé, 1995.

GONÇALVES, Irlen Antônio. CULTURA ESCOLAR: práticas e produção dos grupos escolares em Minas Gerais (1891-1918). Belo Horizonte: Autêntica, 2006.

GUEDES PINTO, Ana Lúcia; FONTANA, Roseli Aparecida Cação. As mulheres professoras, as meninas leitoras e o menino leitor: a iniciação no universo da escrita no patriarcalismo rural brasileiro. Uma leitura a partir de Infância de Graciliano Ramos.

Cad. CEDES [online]. 2004, vol.24, n.63 [cited 2011-09-16], pp. 165-191 . Disponível em:http://www.scielo.br/scielo.php?script=sci_arttext\&pid=S010132622004000200004\&1 ng=en\&nrm=iso $>$. Acesso em: 16 de setembro de 2011, 15h10min.

PEREIRA, Jardel Costa. Cultura e Vida Escolar: O Grupo Escolar de Lavras (1907-1925). In: II Congresso de pesquisa e ensino em Historia da Educação em Minas Gerais. Uberlandia/MG, 2002. v. 1. p. 3-142.

\section{Notas}

${ }^{1}$ possui graduação em Licenciatura em Pedagogia pela Universidade Federal de Viçosa (2012). Desenvolveu trabalho de Iniciação Científica na área de Educação, com ênfase em História da Educação. Atualmente, é pós-graduanda do Mestrado em Educação da Universidade Federal de Viçosa. Email: talitha.cabral@ufv.br

2 possui graduação em História pela Universidade Federal do Rio de Janeiro (1985), mestrado em Educação pela Universidade Federal Fluminense (1993) e doutorado em Educação pela Universidade de São Paulo (2005). É professor Adjunto IV da Universidade Federal de Viçosa, atuando no Programa de Pós-Graduação em Educação (PPGE/UFV), nível de mestrado e em cursos de graduação. Atualmente é avaliador de curso de graduação do Instituto Nacional de Estudos e Pesquisas Educacionais. Tem experiência na área de Educação, com ênfase em História da Educação, atuando principalmente nos seguintes temas: educação, história da educação, política e educação contemporânea e ensino de história. Email: dazevedo@ufv.br

${ }^{3}$ possui graduação em Administração pela Faculdade de Administração de Governador Valadares (1986), graduação em HISTÓRIA pela Fundação Percival Farquhar (2003) e Mestrado em Educação pela Universidade Federal de Minas Gerais (2007). Atualmente é professora de $3^{\circ}$. grau assistente II - de da Universidade Federal de Viçosa. Tem experiência na área de Educação, com ênfase em Educação, atuando principalmente nos seguintes temas: educação, trabalho e sociedade. Email: joanadarcgermano@ gmail.com 
${ }^{4}$ possui graduação em Licenciatura em Pedagogia pela Universidade Federal de Viçosa (2012). Atualmente, é pós-graduando do Mestrado em Educação da Universidade Federal de Viçosa. Email: wagner.gomides@ufv.br

${ }^{5}$ A pesquisa, intitulada "A instalação e constituição do Grupo Escolar nas cidades de Muriaé e Ponte Nova (1907 - 1930): análise de acervo e memórias" foi realizada no Departamento de Educação da Universidade Federal de Viçosa, sob a coordenação do Professor Doutor Denilson Santos de Azevedo, com financiamento dos recursos através da Fundação de Amparo à Pesquisa do Estado de Minas Gerais (FAPEMIG) no período de março de 2010 a janeiro de 2012.

${ }^{6}$ De acordo com Faria Filho (2000, p. 28) a cadeira, era a forma jurídico-institucional de existência de uma turma de ensino primário. Materializava-se numa turma de alunos geralmente de idade bastante variada [...] podia ser subdividida em classes de acordo com o adiantamento daqueles que a frequentavam. [...] os alunos podiam pertencer ao $1^{\circ}, 2^{\circ}, 3^{\circ}, 4^{\circ}$ anos do curso primário.

${ }^{7}$ Nesse modelo educacional, as aulas aconteciam em ambientes cedidos e preparados pelos responsáveis, sem vínculo com o Estado. O pagamento do professor era de responsabilidade do contratante individual ou de um grupo de contratantes. (FARIA FILHO, 2000)

${ }^{8}$ Foi Deputado Estadual pela $2^{\mathrm{a}}$ Circunscrição de Minas Gerais em 2 Legislaturas e Deputado Federal pelo $2^{\circ}$ Distrito de Minas Gerais em 3 Legislaturas.

Recebido em setembro-2012

Aprovado em fevereiro-2013 